Dumitru Cornel Vîlcu

\title{
Reply to Göran Hammarström's comment
}

"Quid ergo tempus? Si nemo ex me querat, scio; si quarenti explicare venim, nescio."

St. Augustine

However strange this may seem, my text was/is not about time (and changes brought by modern philosophers in the understanding of this concept, or rather fundamental reality of our lives), but about the causality behind linguistic change. My main claim is that there can be no 'efficient' cause for a linguistic innovation other than an individual's exerted freedom. Oddly enough, there are philosophers (among which, I consider, Bergson is the most prominent) who state that (a certain degree of) freedom from deterministic conditions in nature can be the source of time. Of course this is by no means a trivial observation, and it may very well give the impression of complicating something which in its nature is very simple. Hammarström says: "Vîlcu, philosophers and others have difficulty understanding time /.../. It is however fortunate for our daily life that most people do not have such difficulty. Through their language they have perfect knowledge of time" etc.

It remains unclear to me what 'language' (preceded by possessive 'their') means in the above mentioned context: Does it refer to a national/ historical/ 'idiomatic' language? If this is the case, I have even bigger difficulties in understanding how a language could provide by itself any knowledge of time. If we take into consideration Coseriu's historical plane of language exclusively, we must remember that words (and all the other significata carriers) do not name beings, but mere possibilities of existence. Thus, a language as such can never say anything about any reality whatsoever. Hammarström also gives a series of examples revealing circularity of definitions, and I totally agree that this is not an exception, but, on the contrary, the rule of a 'langue' manifest in any dictionary.

But even if I misread the presence of the possessive 'their' in Hammerström's sentences quoted above, and it is the universal plane of language, together with the 'general knowledge of things' that we are talking about, then words (and their significata) simply do not matter anymore. Here we have to do with a totally different type of content (designata) and with a level of competence shared, at least virtually, by all human adults, and Hammarström may be right in characterising the most generally accepted 'vision' upon what time is in terms such as measurable-duration-or-distance-between-two-points/moments, etc. (Except, of course, for the 'ahem' part, which involves a meta-linguistic position attainable exclusively in texts, namely, on the third level of language, according to Coseriu.)

Personally, I believe that the time I wrote about should be understood neither as (a) significatum, nor (a) designatum, but as (a) referential sense as it is produced in texts specifically, those written by philosophers. In an interview from a Romanian cultural publication ${ }^{1}$, Coseriu says that humans can relate to language in three different stages: 1. a pre-linguistic stage, in which we manifest immediate physiological reactions to stimuli; if we burn our fingers, we will draw our hand back from the fire, and neither thinking, nor language is involved here; 2. the actual linguistic stage, in which we see reality 'through' the contents

1 "Fiinţă şi limbaj”, [Being and language, Eugenio Coseriu interviewed by Lucian Lazăr], in Echinox, Cluj-Napoca, no. 10-12/ 1996, pages 3-6. 
of words, expressions, etc. in our language; still, we have to remember that, according to Humboldt, languages are not actual descriptions of reality, but ensembles of (virtual) means for describing it; and 3. the post-linguistic stage, in which our language simply becomes an instrument which can be used for different purposes (apophantic, pragmatic, poetic), even for explicitly denying 'intuitions' specific to the second stage (Der Walfisch ist kein Fisch).

It is the third stage which is the most specifically human, and we spend almost all of our lives within it. It is here that our freedom manifests itself, it is here that each and every one of us distinguishes his or her vision of the world from the one passively inherited from their community, parents, ancestors, etc.; moreover, it is here that, through scientific/ 'apophantic' discourse, we can make and sustain claims about realities entering our field of research and investigation. And time is precisely one of those realities... a most fundamental one, I could add.

So, yes, for the pragmatic use of our everyday lives, it may be fortunate that we (also) understand time as some kind of conventionalised space, in which points of reference are marked by clocks synchronised in a framework all over the world. But I can hardly see a more unfortunate procedure than simply 'raising' this common conception to the level of epistemology and use it as a guide in all sciences, including the hermeneutical ones. I'm very much afraid that this is how Hammarström understood Coseriu's vision of science as passage from cognitio clara confusa or distincta inadaequata to cognitio clara distincta adaequata. I say this because, of course, I believe that Coseriu (inspired by Leibniz) is correct, but only as far as description of linguistic-intuitive contents is intended. What I mean is: we cannot scientifically decide what our theoretical and methodological notion of time is by making a poll among everyday speakers of a given language.

According to Coseriu, we have to maintain the (fundamental) epistemological distinction between our field of human/ cultural sciences, on the one side, and the much more 'realistic' (often in the positivist sense of the term) and 'exact' (through experiencing, measuring and calculus) physical and formal-mathematical sciences, on the other side. It seems that, lately, theoretical convictions and methodological devices are again extrapolated from the territory of the so-called 'hard' sciences into the domain of cultural objects. The basic idea behind these extrapolations is that the difference between the two 'realms' would be a difference of degree, not one of nature. And the claim of at least some of our colleagues seems to be the following: there could be a solution of continuity between qualitative and quantitative observations and methods. More exactly, the idea is that what we, 'humanists', so stubbornly call qualitative facts are in fact nothing than a) some very large amount of data and/or b) some very small scale of measurable events which until now were untreatable with mathematical means. But now we have computers which become more and more powerful and rapid and at a given moment they will be able to complete all the necessary calculus in due time. Passing from what was wrongly called 'pure' quality to reasonable, manageable quantity won't take, as it did until now, forever. Quality and quantity are not separated by an eternity.

So, of course, my opinion on this matter is that, far from solving the issue at hand, the above-mentioned theoretical (and methodological) standpoint makes things much more... problematic. Hammarström may be right: philosophers do tend to complicate things; but what I, for instance, have learned (precisely) from such philosophers is that nothing poses a greater danger to a science than a bad meta-theoretical (that is: epistemological) preliminary positioning. But here, of course, there's no disagreement between me and Hammarström or most of the people publishing in this issue of Energeia. 
There remains a difference of opinions, though, as far as time is concerned. My usage above of terms such as 'forever' and 'eternity' wasn't fortuitous. If time as the ultimate substratum of our reality is homogenous, if it bears being subdivided in fixed parts which then can be numbered, then of course one day we will manage to control it technically. But if on the contrary time is freedom, rupture, if it is the very gap between nature and culture, brought into our world by the cultural nature of our beings... well, then it's not a problem which could be solved practically. Should we, then, just stop talking (especially: in a philosophising manner) about it, as the "first Wittgenstein" recommends at the end of his Tractatus? I, for one, will not stop - for you can call me whatever you want, the one thing I'm sure not to be is... a positivist.

\section{P. S: a few words about the oddness of my title -}

On the one hand, I wanted to talk mainly about the direction in which time flows (that is, if it flows at all), precisely because in any positivist approach talking about a cause situated in the future is complete nonsense. But if there is a 'regimen' of time in which it flows backwards (or it stays, as eternal, or it doesn't flow at all, because it's not a characteristic of the universe, but simply a threefold group of 'modes' of our being), the radicalism of the initial claim (we must identify the 'efficient' antecedent, we must measure it, we must establish its exact contribution in today's events or effects) is shown as what I believe it to be - simply a theoretical pretense or, to put it in Coseriu's terms, a grave epistemological confusion.

On the other hand, I decided to preserve an ambiguous position as to how many 'times' there are. And I am not talking about the multiple ways in which normal speakers perceive or describe the flow (or sometimes stillness) of time. I am talking about strict chronology and precise time measurement, specific to physical sciences and their... relative value within the Geisteswissenschaften. Yes, I know that, in terms of natural history, Saussure died almost half a century before Chomsky wrote his main works, so the former has influenced the latter and not the opposite. But I, who live and write in the $21^{\text {st }}$ century, cannot read Saussure without remembering Chomsky's (and many, many others') critiques. Moreover, it is essential, in my line of work, to make people from totally different periods of time 'sit', so-to-say, at the same table and have a reasonable dialogue concerning so-called 'eternal' problems. In short, the (unique, absolute) conception of time as a regular, unidirectional, perfectly measurable flow, which we tend to inherit from physics but also from everyday discourse, is of no particular use in our field, human sciences; on the contrary, it is perhaps the deepest, thus gravest intrusion of quantitative methods in the investigation of (not purely, but fundamentally) qualitative objects. 